\title{
EFFECT OF VITAMIN LEVELS ON BIOMARKERS OF EXPOSURE AND OXIDATIVE DAMAGE - THE EXPAH STUDY
}

\section{Sram R $\mathbf{J}^{a}$, Farmer $\mathbf{P}^{b}$, Singh $\mathbf{R}^{b}$, Garte $\mathbf{S}^{c, d}$, Kalina $\mathbf{I}^{e}$, Popov $\mathbf{T A}^{f}$, Binkova $\mathbf{B}^{a}$, Ragin $\mathbf{C}^{c}$, Taioli E. ${ }^{c}$}

${ }^{a}$ Laboratory of Genetic Ecotoxicology, Institute of Experimental Medicine of Academy AS CR and Health Institute of Central Bohemia,, Prague, Czech Republic

${ }^{b}$ Cancer Biomarkers and Prevention Group, Biocentre, University of Leicester, UK

c University of Pittsburgh Cancer Institute, Pittsburgh PA, USA

${ }^{d}$ Genetics Research Institute ONLUS, Milan, Italy

${ }^{e}$ Department of Medical Biology, Medical Faculty University P.J. Šafárik, Košice, Slovak Republic

${ }^{f}$ National Center of Public Health Protection, Sofia, Bulgaria

Corresponding author: Emanuela Taioli, MD, PhD

University of Pittsburgh Cancer Center

5150 Centre Avenue

Pittsburgh, PA 15232

USA

Phone: +412623 2217

Fax: +412 6233878

email: taiolien@upmc.edu 


\section{ABSTRACT}

DNA adducts are markers of carcinogen exposure and of their biological effect; they have been shown to be related to mutagenesis, and therefore they could be a predictive biomarker of human cancer.. The objective of this study was to assess if there is a relationship between vitamins $A, C$, and $E$, which are known to play a significant role as free radical scavengers and antioxidant agents, and biomarkers of genotoxicity and oxidative stress.

Three hundred and fifty-six subjects from Czech Republic, Slovak Republic and Bulgaria, who completed a questionnaire on dietary information and had a measurement of plasma $A, C, E$ vitamins, DNA adduct levels (benzo[a]pyrene (B[a]P) and bulky (DNA-Tot) DNA adducts) and oxidative damage (cyclic pyrimidopurinone $\mathrm{N}-1, \mathrm{~N} 2$ malondialdehyde -2 deoxyguanosine (M1dG) and 8-oxo-7,8-dihydro2_deoxyguanosine (8-oxodG)) were analyzed.

A significant inverse correlation was observed between plasma vitamin levels and both benzo[a]pyrene $(\mathrm{B}[\mathrm{a}] \mathrm{P})$ and bulky DNA adducts. Vitamin $\mathrm{A}$ was also significantly inversely correlated with M1dG, a marker of oxidative damage. The associations were stronger in non smokers than in smokers.

Dietary intake of certain antioxidants such as vitamins is associated with reduced levels of markers of DNA damage (B[a]P and DNA-Tot) and oxidation (M1dG and 8-oxodG) measured in peripheral white blood cells. This could contribute to the protective role of such a dietary pattern on cancer risk. The protective effect of dietary vitamins is less evident in smokers. 


\section{INTRODUCTION}

Diet may be the source of several mutagens, such as aflatoxin and heterocyclic amines, whose biological effects on DNA have been studied extensively. Other carcinogens present in diet, such as polycyclic aromatic hydrocarbons (PAH) and other aromatic compounds have been investigated less frequently. $\mathrm{PAH}$ may occur in fried and charcoal-grilled meat or in the food chain as a result of environmental pollution $(1,2)$. PAHs are an important class of carcinogens, capable of inducing the formation of DNA adducts leading to DNA damage after metabolic activation (3). This process may modify the long term individual cancer risk, at least with respect to lung cancer, as reported recently by a meta and pooled analysis (4). The measure of genotoxicity in target organs such as lung, bladder and colon in relation to exposure seems to bring less convincing evidence (5).

Preliminary to the study of the effect of diet on cancer risk is the study of the biological effects of dietary constituents in healthy subjects. Data from large cohort studies have been published on the association between dietary components and DNA adducts measured in peripheral blood. An inverse association between fruit and/or vegetable intake and various measure of DNA damage in healthy subjects has been repeatedly reported in the European Prospective Investigation into Cancer and Nutrition (EPIC) study $(6,7)$.

In a previous analysis of the present EXPAH cohort (8), the relationship between dietary factors and DNA damage was examined by assessing whether specific groups of foods known to have antioxidant properties would be inversely associated with levels of DNA adduct levels, oxidative damage to DNA and chromosomal aberrations. The results of this analysis showed modest, if any, associations between such dietary components and biomarkers of DNA damage.

In order to better understand mechanisms through which diet affects DNA damage, it is useful to look at the effect exerted by the various micronutrients contained in diet.

Dietary vitamins and antioxidant consumption may modify the levels of DNA damage induced by both diet and smoking, the main source of PAH exposure, thus modifying individual cancer risk. The association between dietary vitamins and DNA damage/oxidation is usually investigated indirectly by calculating vitamin consumption from dietary items collected through standardized questionnaires. However, the association between vitamin levels as measured in plasma on several measures of DNA damage and oxidation has been rarely performed. A study on 109 non smoking policemen conducted in Prague, reported a weak negative association between plasma vitamin A levels and both Total DNA adducts and B[a]P-like DNA adducts (9).

Another study from the same group on a small population of 50 bus drivers showed that vitamin $E$ levels were positively correlated with markers of oxidative stress (10).

Vitamin $C$ (ascorbic acid) is one of the most important natural antioxidants in living tissues (11). Studies conducted in the early 80 s (12) showed a clear-cut ability of vitamin $\mathrm{C}$ to block the clastogenic action of alkylating agents. Subsequently to this finding, vitamin $\mathrm{C}$ was administered as a prophylactic agent in several groups of 
workers occupationally exposed to different mutagens and carcinogens (13-16). Vitamin $\mathrm{C}$ prophylaxis significantly decreased the frequency of aberrant cells in these workers.

The present analysis investigates the role of vitaminA, C, E measured in plasma on markers of DNA damage (B[a]P and DNA-Tot) and oxidative stress (M1dG and 8oxodG) in a healthy population collected in three geographical areas of Europe. 


\section{METHODS}

The population under study is described in detail elsewhere $(17,18)$, and consisted of 204 workers selected from Prague (Czech Republic) (city policemen), Kosice (Slovak Republic) (city policemen), and Sofia (Bulgaria) (city policemen and bus drivers), and 152 subjects who were non-occupationally exposed to traffic pollutants, matched for age and gender. Blood samples were collected from each participant for determination of DNA adducts levels, genetic susceptibility, and determination of other biomarkers, such as vitamins and folates. A questionnaire was completed by each individual providing demographic, smoking and dietary information.

Smoking status was defined according to cotinine levels (adjusted by creatinine levels): smokers were subjects with cotinine levels greater than $500 \mathrm{ng}$ cotinine/mg of creatinine, passive smokers were subjects with cotinine levels between 200 and $500 \mathrm{ng}$ cotinine/mg, and non smokers with cotinine levels lower than $200 \mathrm{ng}$ cotinine/mg.

BLOOD SAMPLES: The blood samples were were collected at the end of the working shift and processed into serum, plasma, erythrocytes and lymphocytes, and distributed to the partner laboratories using random assigned codes to assure anonymity. All the samples were kept frozen until shipment or analysis, and were transported to the laboratories in dry ice, and then stored at $-80 \circ \mathrm{C}$ until usage.

In addition to job description, personal exposure was obtained with the use of personal monitors. Subjects were classified as exposed when personal exposure to carcinogenic PAHs (c-PAHs) was greater than the median value of average exposure of non occupationally exposed subjects, i.e. $7.55 \mathrm{ng} / \mathrm{m} 3$, and as non exposed when personal exposure values were lower or equal to $7.55 \mathrm{ng} / \mathrm{m} 3$.

Personal Monitors: The individual exposures of the subjects under study were determined during their working shift by the use of personal monitors, which collected PM2.5 from which the c-PAHs were extracted. Personal monitors were worn once by each subject, were applied at the beginning of the work shift, and collected at the end of it.

Carcinogenic PAHs, (benz[a]anthracene, chrysene, benzo[b]fluoranthene, benzo[k]fluoranthene, benzo[a]pyrene (B[a]P), dibenzo[a,h]anthracene, benzo[g,h,i]perylene andindeno[1,2,3-cd]pyrene) and phenanthrene, anthracene, fluoranthene, pyrene, coronene, were determined in the filter extracts by HPLC with fluorescence detection (NIOSH method 5506).

As a measure of oxidative DNA damage, 8-oxodG was determined in post-shift lymphocyte DNA samples from 98 exposed individuals and 105 controls from Prague and Kosice (19). A second measurement of oxidative stress was malondialdehyde DNA 
adduct (M1dG) in post-shift lymphocyte DNA from 198 exposed and 156 control individuals from all three cities.

8-oxodG levels were determined by liquid chromatography-tandem mass spectrometry multiple reaction monitoring (LC-MS/MS MRM) technique, using immunoaffinity or HPLC purification of 8-oxo-dG (19). This technique was also recommended by the ESCODD guidelines (20). M1dG DNA adduct was measured by immunoslot blot procedure described in detail elsewhere (21).

As biomarkers of exposure to c-PAHs, total PAH-DNA (bulky) adducts and the specific adduct arising from $\mathrm{B}[\mathrm{a}] \mathrm{P}$ (B[a]P-like DNA adduct) were measured in lymphocyte DNA, using ${ }^{32} \mathrm{P}$-postlabelling and following protocols described elsewhere (22).

Vitamin C (ascorbic acid) was determined in plasma using a HPLC as previously described (23). Vitamin E (alpha-tocopherol) and vitamin A were determined by using a HPLC-UV detection method described by Driskell et al. following $n$-heptane extraction from the plasma (24). The CEDIA folate kit (Roche Diagnostics, Prague, Czech Republic) was used for the determination of folates in plasma. Chromosome aberrations were measured by fluorescence in situ hybridization (FISH) $(25,26)$.

\section{STATISTICAL ANALYSIS}

Data were transformed when appropriate to obtain normality of the distribution of each variable. The correlations between vitamin levels and biomarkers of oxidative DNA damage (8-oxodG and M1dG adducts levels) and environmental exposure (bulky DNA adducts and B[a]P DNA adducts levels) were assessed by Pearson correlation analysis. Multiple linear regression models were used to assess the independent contribution of exposure, age, vitamin levels and smoking to the levels of each biomarker of exposure or oxidative damage. $F$ values and corresponding $p$ values are reported.

A $p$-value lower than 0.05 was considered as statistically significant. All the statistical analyses were performed using SAS statistical package (8.1 Version, SAS Institute Inc., Cary, NC).

\section{RESULTS}

The average age of the population was $34.1 \pm 9.0$ years; $39.1 \%$ of the subjects were current smokers, the average c-PAHs exposure measured with personal monitors was $22.0 \pm 26.5 \mathrm{ng} / \mathrm{m3}$, with the highest findings in Bulgaria, followed by the subjects recruited in Slovakia, and then by the subjects from the Czech Republic.

The mean values of plasma vitamins are reported in table 1 . There was a high variability in values across subjects, as shown by the wide ranges of values. 
The correlation between vitamin levels and the various biomarkers of genotoxicity/oxidative damage is reported in table 2 and figures 1 and 2 . There was a significant inverse correlation between the B[a]P-like DNA adduct and vitamin $\mathrm{C}$ (fig 1, a), A (figure 2, a), and $E$ levels (Table 2). The correlation was stronger in non smokers than in current smokers. Total DNA adducts were also statistically inversely associated with vitamin $C$ (figure 1, b), A (figure 2, b), E levels (Table 2); for vitamin $E$, the association was stronger in non smokers. A weak positive association between vitamin $A$ and 8-oxodG was observed (Table 2). Vitamin A levels were significantly inversely associated with M1dG adducts (Table 2, figure 2, c). There was no significant correlation between chromosomal aberrations by FISH and vitamin levels. The analysis of subjects exposed to passive smoking seems to follow the direction of the analysis conducted in non smokers, although the reduced number of subjects does not allow a detailed analysis of this subgroup.

The multivariate analysis of the determinants on DNA adduct levels is presented in table 3. Total DNA adducts remain significantly inversely associated with both vitamin A and $C$ in non smokers, after adjustment for potential confounders (age, exposure status and levels of the other vitamins). In smokers, only vitamin A showed a significant inverse association with total DNA adducts. For the B[a]P-like DNA adduct, the only significant inverse association shown by the multivariate analysis was with vitamin $E$ in non smokers. No significant association was observed between 8oxodG and any of the vitamins considered in this study. M1dG levels were significantly inversely associated with vitamin $A$ in non smokers, and with vitamin $C$ in smokers, after adjustment for possible confounders. 


\section{DISCUSSION}

Our study, conducted on a sample of healthy volunteers from three European Countries, shows a significant inverse association between vitamin $A, C$ and $E$ and both total and $\mathrm{B}[\mathrm{a}] \mathrm{P}$-like DNA adducts; in the multivariate analysis, total DNA adducts resulted independently associated with both vitamin $A$ and $C$ levels, while for $B[a] P$-like DNA adducts only the association with vitamin $E$ levels persisted after adjustment for possible confounders.

The significant inverse associations between vitamin levels and bulky DNA adducts observed in the present analysis were almost always confined to non smokers. The literature on this aspect is scarce and not univocal. A published study with similar design to the present study reported an association confined to DNA adducts and exposure to environmental tobacco smoke, and a possible interaction with dietary components in this group (27). However, another study conducted in the Czech Republic in healthy non smokers did not find any association between DNA adduct levels in lymphocytes and plasma vitamin $C$ levels, while reported a protective effect of vitamin A on DNA adducts production under conditions of elevated exposure to c-PAHs. In line with our findings, a recent report from EPIC (European Prospective Investigation into Cancer and Nutrition, indicated that leucocyte DNA adducts may predict lung cancer risk among never and former smokers (28), although vitamins were not directly measured in the EPIC study, but deduced from the various dietary items. One reason for the observed inverse associations between DNA damage and vitamin levels in non smokers could be that the subjects are exposed to environmental tobacco smoke, and that vitamins are counteracting the deleterious effects of such exposure. An association between DNA damage and ETS exposure in children has been reported (29). In our analysis, we were able to adjust the findings for the level of environmental exposure to PAHs, since detailed personal measurements were performed at the time of enrollment. We also used cotinine levels in order to classify subjects according to their smoking status, since the reported information on passive smoking exposure were very limited. The analysis of passive smokers gave results similar to what observed in non smokers; however the small number of subjects included in this category does not allow to draw any firm conclusion.

A previously published paper using this data set (30), conducted with the purpose of understanding the determinants of markers of DNA oxidative damage and the interaction with metabolic gene polymorphisms has partially explored the association between M1dG and 8-oxodG and vitamin levels; however the analysis was focused on geographic differences in determinants of biomarker levels, and was not conducted with the same statistical depth as it is in the present paper.

Our study also indicates that vitamin levels measured in plasma do not correlate with markers of oxidative damage such as M1dG and 8-oxodG adducts, while they do correlate with bulky DNA adducts and BPa DNA adducts. It is possible that different mechanisms of DNA repair, as well as differences in the way vitamins interact with 
markers of DNA damage, play a role in determining this result. Both M1dG and 8oxodG adducts showed a weak correlation with vitamin A levels, which persisted for M1dG only at the mutivariate analysis, where the data were adjusted for possible confounders; in this analysis, age became the predominant independent determinant of oxidative damage. Similar findings were reported by a study conducted in five European countries (31), and by a study involving men on high fruit and vegetable diets (32). A study involving coke-oven workers who took vitamin supplements showed that the excretion of 8-oxodG adducts was decreased compared to those workers that took no vitamins (33). However, the study did not include direct measurements of plasma vitamin levels were not measured. In addition, occupational exposure to c-PAHs in coke-oven workers is approx. two-three orders of magnitude higher than what measured from environmental exposure.

There may be basic underlying differences in the biological effects exerted on oxidative damage by vitamins deriving from a regular balanced diet in comparison to vitamins deriving from a diet including vitamin supplements. This aspect needs to be clarified by further studies.

No association was found between markers of chromosomal aberration as measured by FISH and plasma vitamin levels in the present study. According to previous experience (13-16), the effect of vitamins on DNA damage depends on the amount of vitamins consumed, and it is evident when vitamin supplements are administered. In this study, the negative results are probably related to the fact that approximately $50 \%$ of the population exhibited a dietary intake of vitamin C below the levels observed in dietary vitamin supplements are administered.

Strength of this study, in addition to the large sample size, is the fact that the cohort is well characterized epidemiologically, and that numerous biomarkers are measured in each subject. The direct measure of plasma vitamin levels, rather that their indirect calculation from a dietary questionnaire, is another factor that add strength to our results.

In conclusion, our study seems to indicate that vitamin levels may modulate direct signs of genotoxicity in healthy subjects, and that such effect is more pronounced in non smokers. This result adds data to the field of chemoprevention with multivitamins in smokers, but also reinforces the need for a diet rich in vitamin components for the general population. 
Acknowledgement. The European Commission "Quality of life and management of living resources" program (QLK4-2000-00091) and the Medical Research Council (G0100873) are gratefully acknowledged for financial support. 
Table 1: General characteristics of the population and average values of vitamins as measured in plasma

$\begin{array}{lllll}\text { Variable } & \text { N subjects } & \text { Mean } & \text { Std. Dev. } & \text { Range } \\ \text { Age (years) } & 356 & 34.1 & 9.0 & 19-65 \\ \text { C-PAHs exposure }(\mathrm{ng} / \mathrm{m} 3) & 347 & 22.0 & 26.5 & 3.05-263.3 \\ \text { VIT C }(\mu \mathrm{mol} / \mathrm{l}) & 329 & 48.6 & 41.84 & (0.2-282.86) \\ \text { VIT A }(\mu \mathrm{mol} / \mathrm{l}) & 354 & 2.37 & 2.07 & (0.05-9.80) \\ \text { VIT E }((\mu \mathrm{mol} / \mathrm{l}) & 354 & 18.22 & 9.34 & (2.8-118.55)\end{array}$


Table 2: Correlation between vitamins and DNA adducts

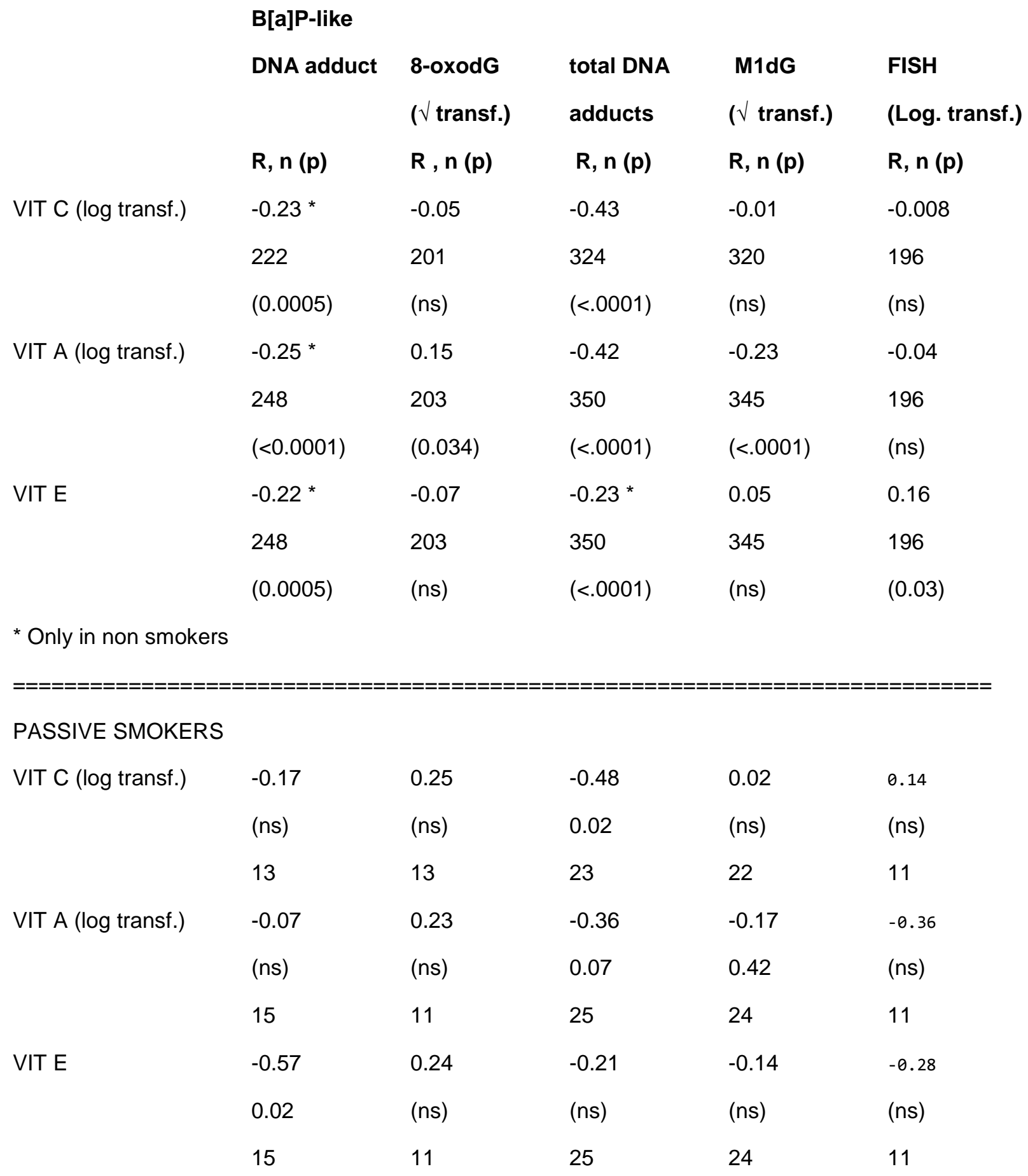


Fig. 1 - Correlation between Vitamin C levels (log transformed) and B[a]P-like DNA adduct (a), and total DNA adducts (b)

(a)

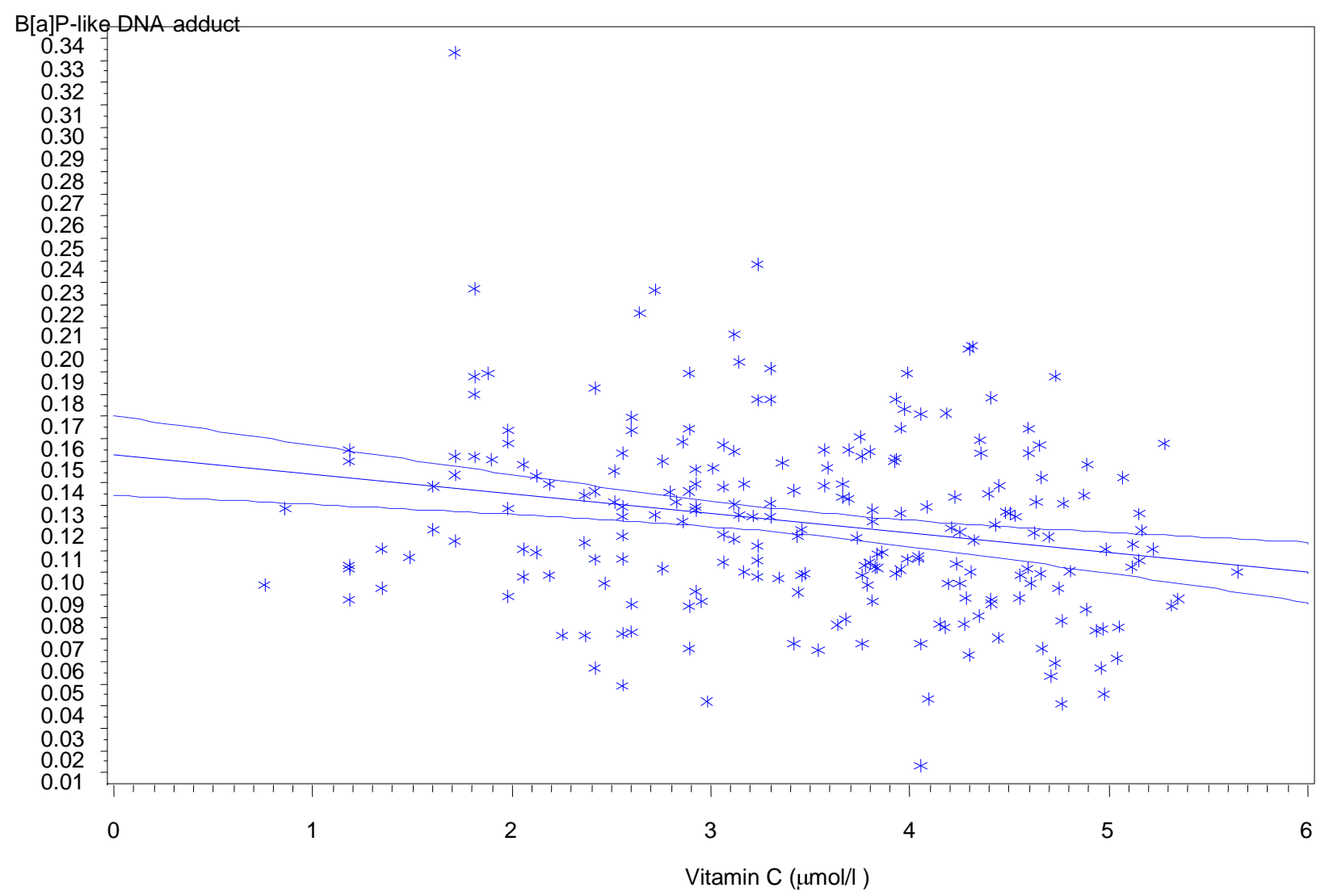


(b)

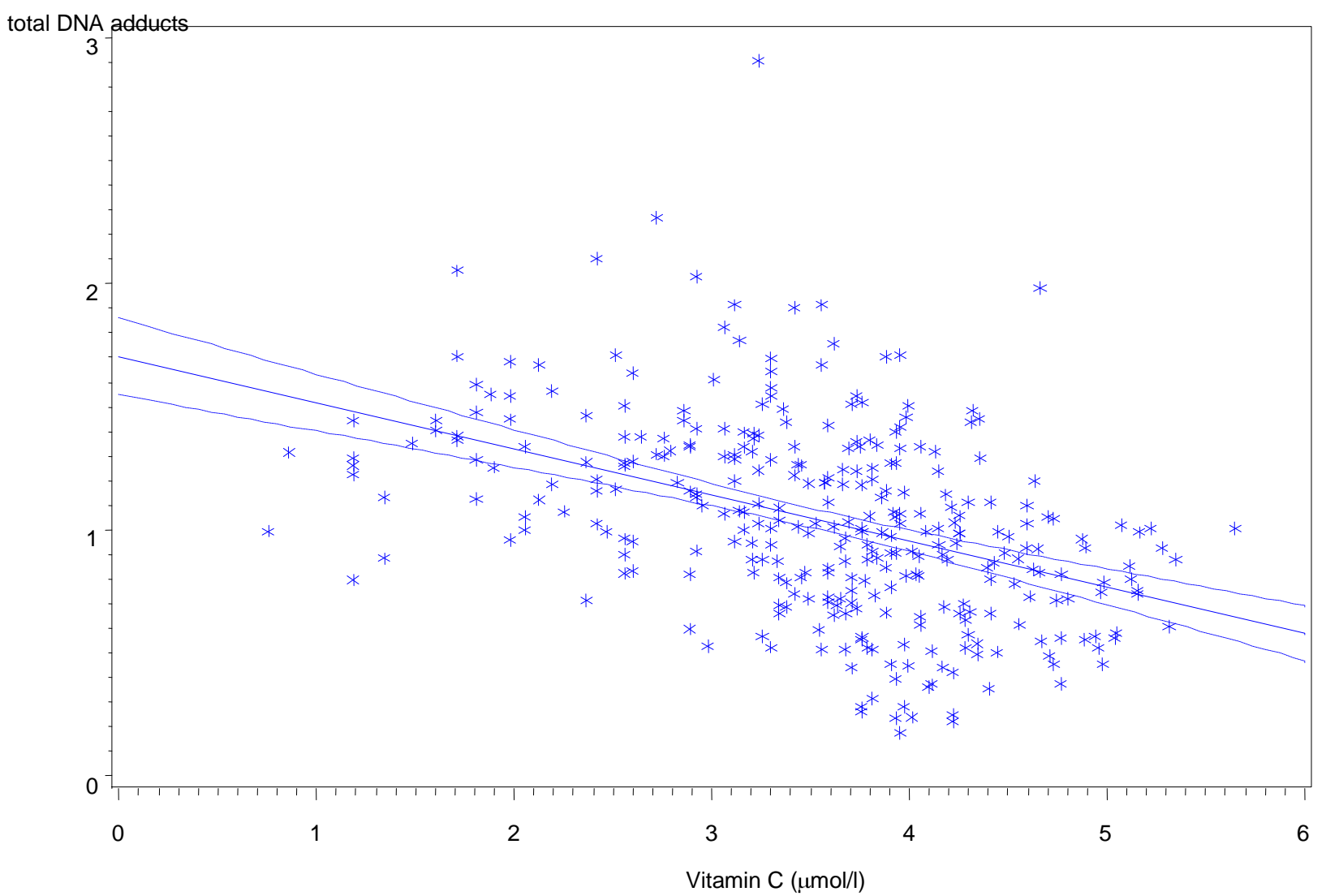


Fig. 2 - Correlation between Vitamin A levels (log transformed) and B[a]P-like DNA adduct (DNA_BP) (a), total DNA adducts (DNA_TOT) (b), and malondialdehyde DNA (M1) adducts (c) (malondialdehyde DNA (M1) adducts are squared transformed)

(a)

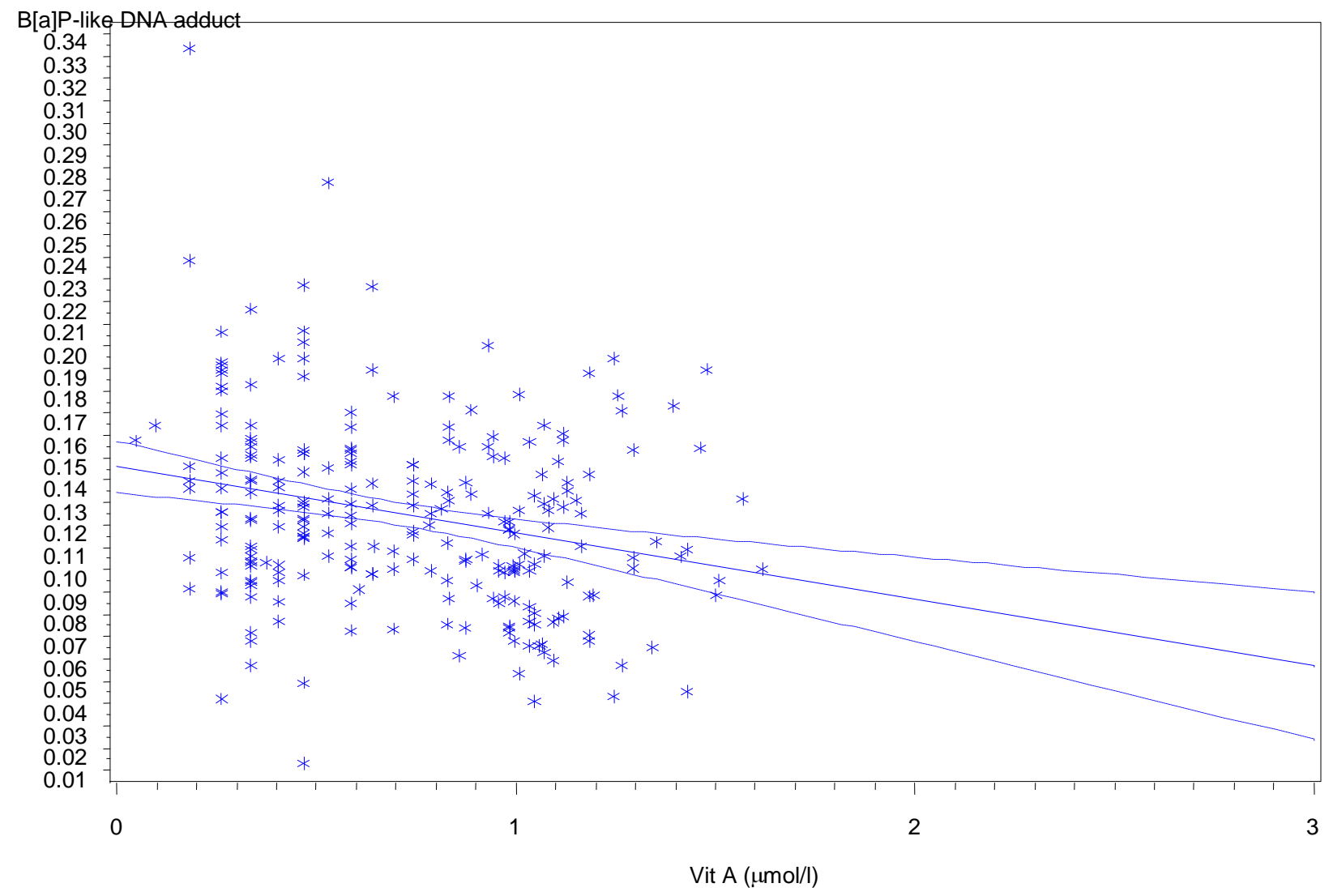


(b)

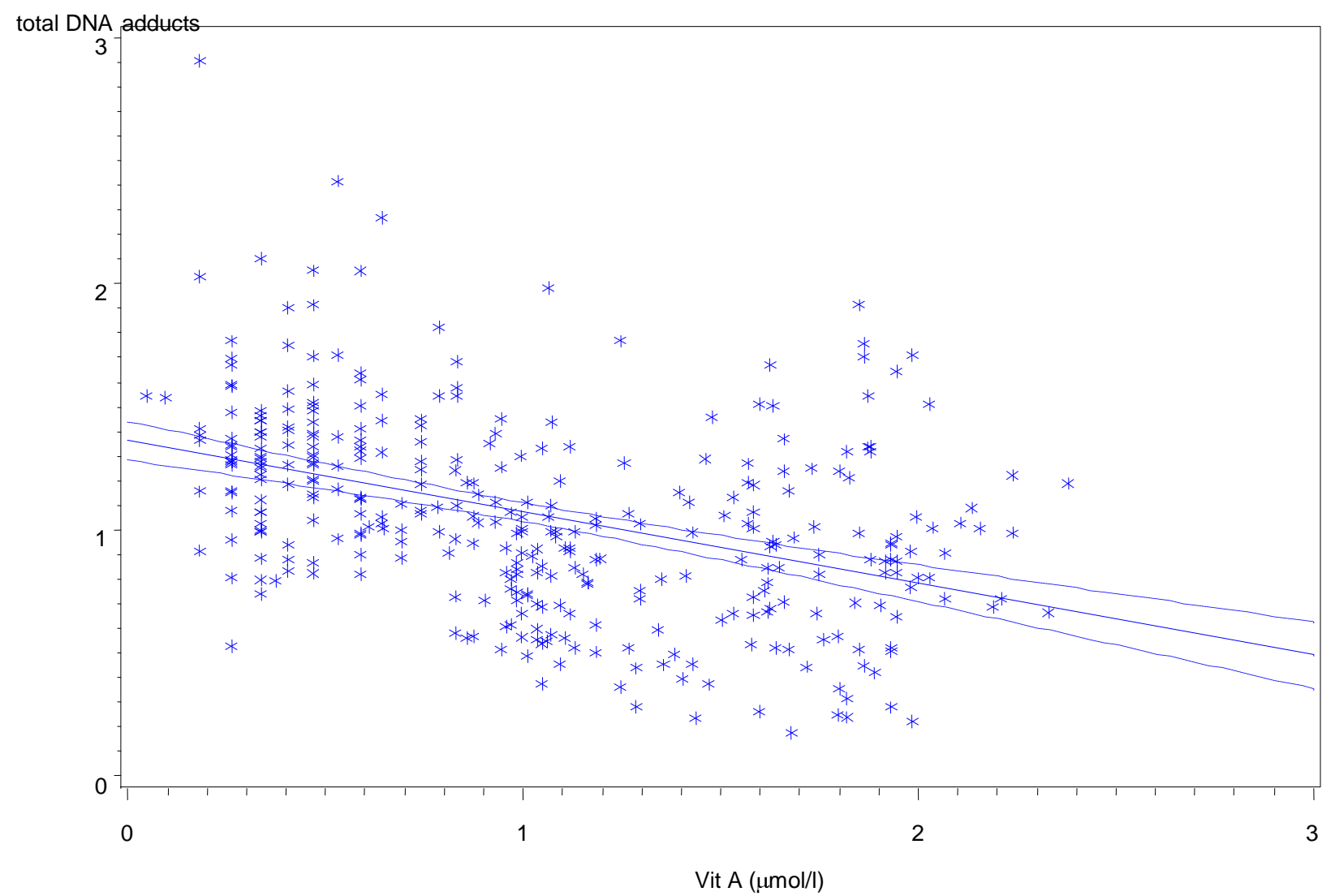


(c)

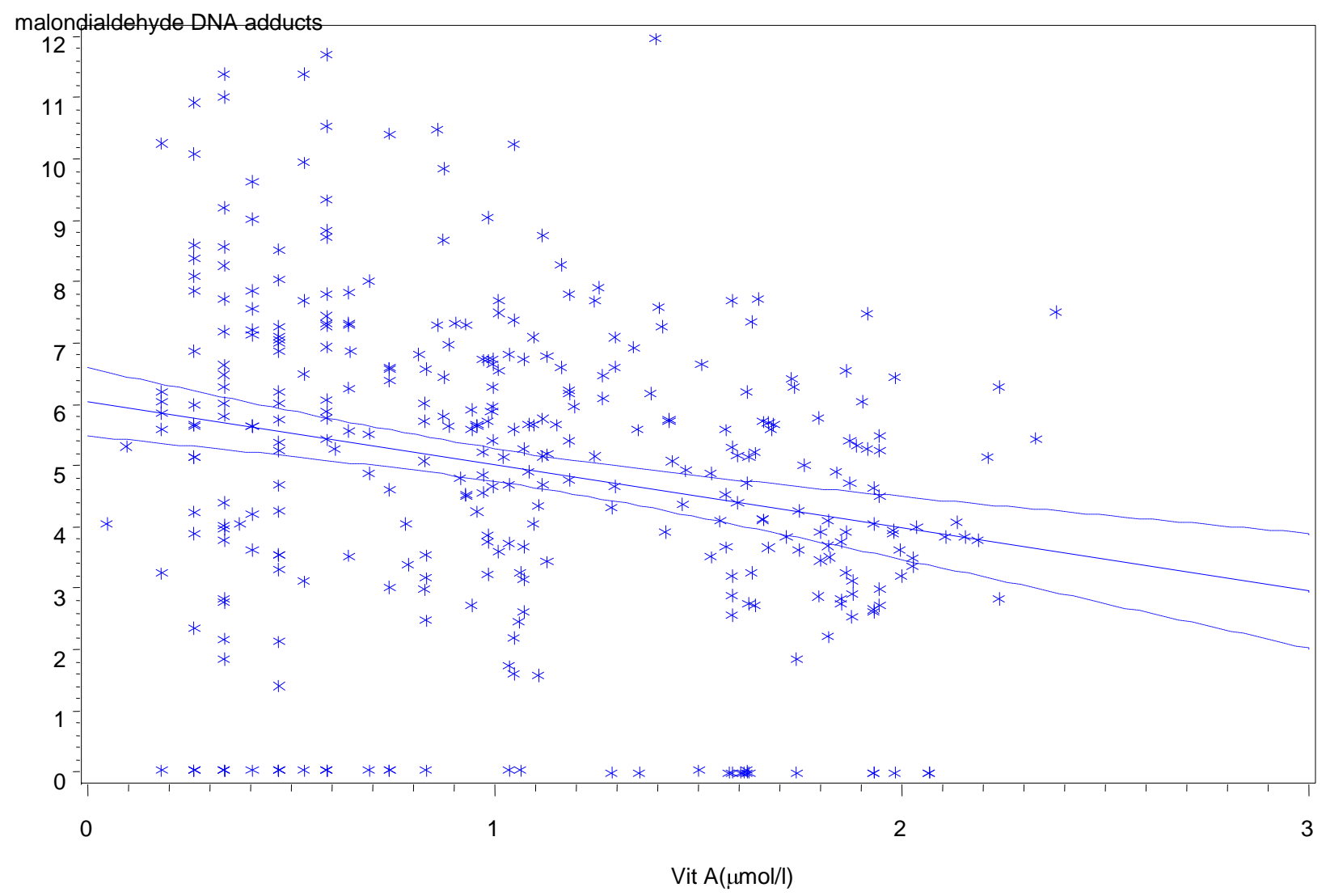


Table 3: independent contribution of several variables to the levels of adducts in peripheral lymphocytes -multivariate linear analysis

NON SMOKERS

\section{Total DNA adducts}

Variable

Age (years)

Vit. $E(\mu \mathrm{mol} / \mathrm{l})$

Vit. A ( $\mu \mathrm{mol} / \mathrm{l})$

Vit. $C(\mu \mathrm{mol} / \mathrm{l})$

Exposure

F Value

0.05

2.44

22.88

10.81

3.78
B[a]P-like DNA adduct

Age (years)

2.95

Vit. $E(\mu \mathrm{mol} / \mathrm{l})$

4.76

Vit. A ( $\mu \mathrm{mol} / \mathrm{l})$

1.64

Vit. C $(\mu \mathrm{mol} / \mathrm{l})$

0.01

Exposure

$(>/ \leq 7.55 \mathrm{ng} / \mathrm{m} 3)$

\section{8 oxodG}

Age (years)

Vit. E ( $\mu \mathrm{mol} / \mathrm{l})$

Vit. A $(\mu \mathrm{mol} / \mathrm{l})$

Vit. C $(\mu \mathrm{mol} / \mathrm{l})$

Exposure

$(>/ \leq 7.55 \mathrm{ng} / \mathrm{m} 3)$

\section{M1dG}

Age (years)

Vit. $E(\mu \mathrm{mol} / \mathrm{l})$

Vit. A $(\mu \mathrm{mol} / \mathrm{l})$

Vit. C $(\mu \mathrm{mol} / \mathrm{l})$

Exposure
4.02

0.23

9.17

0.14

2.67

1.36

3.36

1.21

0.75

1.38
0.09

0.03

0.20

0.94

0.35

0.001

0.05

\section{SMOKERS}

$\begin{array}{ll}\text { F Value } & p \\ 0.59 & 0.44 \\ 0.05 & 0.82 \\ 12.71 & 0.0005 \\ 3.06 & 0.08 \\ 0.53 & 0.47\end{array}$

0.15

0.69

$\begin{array}{ll}1.21 & 0.27\end{array}$

$0.19 \quad 0.66$

$0.17 \quad 0.68$

$0.58 \quad 0.44$

$0.12 \quad 0.73$

$3.01 \quad 0.09$

$0.00 \quad 0.95$

$1.35 \quad 0.25$

35

$\begin{array}{lll}0.39 & 0.87 & 0.35\end{array}$

$\begin{array}{lll}0.07 & 0.00 & 0.95\end{array}$

0.27 
$(>/ \leq 7.55 \mathrm{ng} / \mathrm{m} 3)$

\section{REFERENCES}

1) Jakszyn P, Agudo A, Ibanez R, et al. Development of a food database of nitrosamines, heterocyclic amines, and polycyclic aromatic hydrocarbons. J Nutr 2004; 134: 2011-2014.

2) Phillips DH. Polycyclic aromatic hydrocarbons in the diet. Mutat Res 1999; 443: 139-147.

3) International Agency for Research on Cancer-Polynuclear Aromatic Compounds, Part 1, Chemical, Environment and experimental Data. IARC Monographs on the Evaluation of the Carcinogenic Risks to Humans 1983; no. 32, pp. 1-453. Lyon, France: IARC Press.

4) Veglia F, Loft S, Matullo G et al. for the Genair-EPIC investigators. DNA adducts and cancer risk in prospective studies: a pooled analysis and a meta-analysis. Carcinogenesis. 2008; 29(5):932- 6

5) Taioli E, Gene-environment interaction in tobacco-related cancers. Carcinogenesis 200829 (8): $1467-74$

6) Palli D, Masala G, Vineis $P$, et al. Biomarkers of dietary intake of micronutrients modulate DNA adduct levels in healthy adults. Carcinogenesis 2003; 24: 739-746.

7) Peluso M, Airoldi L, Munnia A, et al. Bulky DNA adducts, 4-aminobiphenyl-haemoglobin adducts and diet in the European Prospective Investigation into Cancer and Nutrition (EPIC) prospective study. Br J Nutr 2008; 100(3):489-95

8) Raimondi S, Garte S, Sram RJ, et al. Effects of diet on biomarkers of exposure and effects, and on oxidative damage. Mutat Res 2007; 620: 93-102

9) Topinka J, Sevastyanova O, Binkova B, et al. Biomarkers of air pollution exposure-A study of policemen in Prague. Mutat Res 2007; 624: 9-17

10) Rossner P, Svecova V, Milcova A, Lnenickova Z, Solansky I, Santella RM, Sram RJ. Oxidative and nitrosative stress markers in bus drivers. Mutat Res 2007; 617: 23-32

11) Shamberger RJ. Genetic toxicology of ascorbic acid. Mutat Res 1984; 133: 135-159.

12) Gebhart E, Wagner $\mathrm{H}$, Crziwok K, Behnsen $\mathrm{H}$. The action of anticlastogens in human lymphocyte cultures and their modification by rat-liver $S 9$ mix. II. Studies with vitamins $C$ and $E$. Mutat Res 1985; 149: 83-94.

13) Sram RJ, Dobias L, Pastorkova A, Rossner P, Janca L. Effect of ascorbic acid prophylaxis on the frequency of chromosome aberrations in the peripheral lymphocytes of coal-tar workers. Mutat Res 1983; 120: 181-186.

14) Sram RJ, Hola N, Kotesovec F, Vavra R. Chromosomal abnormalities in soft coal open-cast mining workers, Mutat Res 1985; 144: 271-275. 
15) Sram RJ, Cerna M, Hola N. Effect of ascorbic acid prophylaxis in groups occupationally exposed to mutagens, In: Genetic Toxicology of Environmental Chemicals, Part B: Genetic Effects and Applied Mutagenesis. A.R.Liss Inc., 1986, p.327-335.

16) Sram RJ, Samkova I, Hola N. High-dose ascorbic acid prophylaxis in workers occupationally exposed to halogenated ethers. J Hyg Epidemiol Microbiol Immunol 1983; 27: 305-318.

17) Taioli E, Sram RJ, Kalina I, Popov TA, Farmer PB. Effects of polycyclic aromatic hydrocarbons (PAHs) in environmental pollution on exogenous and oxidative DNA damage (EXPAH). Description of the population under study. Mutat Res 2007; 620: 1-6.

18) Farmer PB, Singh R, Kaur B, et al. Molecular epidemiology studies of carcinogenic environmental pollutants. Effects of polycyclic aromatic hydrocarbons (PAHs) in environmental pollution on exogenous and oxidative DNA damage, Mutat Res 2003; 544: 397-402.

19) Singh R, McEwan M, Lamb JH, Santella RM, Farmer PB. An improved liquid chromatography/tandem mass spectrometry method for the determination of 8-oxo-7,8-dihydro2-deoxyguanosine in DNA samples using immunoaffinity column purification. Rapid Commun Mass Spectrom 2003; 17: 126-134.

20) ESCODD, Inter-laboratory validation of procedures for measuring 8-oxo-7,8-dihydroguanine/8-oxo7,8-dihydro-2_-deoxyguanosine in DNA, Free Radic. Res. 36 (2002) 239-245.

21) R. Singh, C. Leuratti, S. Josyula, M.A. Sipowicz, B.A. Diwan, K.S. Kasprzak, H.A.J. Schut, L.J. Marnett, L.M. Anderson, D.E.G. Shuker, Lobe-specific increases in malondialdehydeDNA adduct formation in the livers of mice following infection with Helicobacter hepaticus, Carcinogenesis 22 (2001) 1281- 1287.

22) Binkova B, Topinka J, Mrackova G. Coke oven workers study: the effect of exposure and GSTM1 and NAT2 genotypes on DNA adducts in white blood cells and lymphocytes as determined by 32P-postlabeling, Mutat Res 1998; 446: 67-84.

23) Tanishima K, Kita M. High-performance liquid chromatographic determination of plasma ascorbic acid in relationship to health care. J Chromatogr 1993; 613: 275-280.

24) Driskell WJ, Neese JW, Bryant CC, Bashor MM. Measurement of vitamin A and vitamin E in human serum by high-performance liquid chromatography. J Chromatogr 1982; 231: 439-444.

25) Lucas JN, Poggenesse M, Straume T. Translocations between two specific human chromosomes detected by three-color "chromosomes painting", Cytogenet. Cell Genet. 1993; 62: 11-12.

26) Tucker JD, Morgan WF, Awa AA, Bauchinger M, Blakey D, Cornforth MN, Littlefield LG, Natarajan AT, Shasserre C. A proposed system for scoring structural aberrations detected by chromosome painting, Cytogenet. Cell Genet. 1995; 68: 211-221.

27) Georgiadis P, Topinka J, Stoikidou M, et al. AULIS Network. Biomarkers of genotoxicity of air pollution (the AULIS project): bulky DNA adducts in subjects with moderate to low exposures 
to airborne polycyclic aromatic hydrocarbons and their relationship to environmental tobacco smoke and other parameters. Carcinogenesis 2001; 22: 1447-1457.

28) Airoldi L, Vineis $P$, Colombi $A$, et al. 4-Aminobiphenylhemoglobin adducts and risk of smoking-related disease in never smokers and former smokers in the European Prospective Investigation into Cancer and Nutrition prospective study. Cancer Epidemiol Biomarkers Prev 2005; 14: 2118-2124.

29) Zalata, S. Yahia, A. El-Bakary, H. M. Elsheikha. Increased DNA damage in children caused by passive smoking as assessed by comet assay and oxidative stress. Mutat Res 2007; 629: 140-147

30) Singh R, Sram RJ, Binkova B, Kalina I, Popov TA, Georgieva T, Garte S, Taioli E, Farmer PB. The relationship between biomarkers of oxidative DNA damage, polycyclic aromatic hydrocarbon DNA adducts, antioxidant status and genetic susceptibility following exposure to environmental air pollution in humans. Mutation Research 2007; 620 83-92

31) Collins AR, Gedik CM, Olmedilla B, Southon S, Bellizzi M. Oxidative DNA damage measured in human lymphocytes: large differences between sexes and between countries and correlations with heart disease mortality rates. FASEB J 1998; 12: 1397-1400.

32) Hertog MGL, De Vries A, Ocke MC, Schouten A, Bueno de Mesquita HB, Verhagen $H$. Oxidative DNA damage in humans: comparison between high and low habitual fruit and vegetable consumption. Biomarkers 1997; 2: 259-262.

33) Wu M-T, Pan C-H, Huang Y-L, Tsai P-J, Chen C-J, Wu T-N. Urinary excretion of 8-hydroxy2_-deoxyguanosine and 1- hydroxypyrene in coke-oven workers. Environ Mol Mutagen 2003; 42: 98-105.

\section{ACKNOWLEDGEMENTS}

The authors acknowledge the European Commission 'Quality of life and management of living resources' programme (QLK4-CT-2000-00091) for financial support. 